\title{
Elevated water temperature increases the levels of reo-like virus and selected innate immunity genes in hemocytes and hepatopancreas of adult female blue crab, Callinectes sapidus
}

J. Sook Chung ${ }^{1 *}$, J. S. Pitula ${ }^{2}$, E. Schott ${ }^{1}$, J. V. Alvarez ${ }^{1}$, L. Maurer ${ }^{1}$, and K. A. Lycett ${ }^{2}$

Anne, MD, 21853, USA

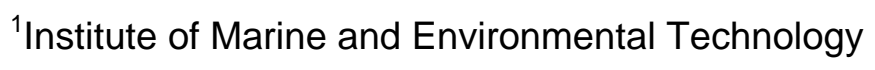

${ }^{*}$ Corresponding author 


\section{Abstract}

Seasonal changes in water temperature directly affect the aquatic ecosystem. The blue

3 crab, Callinectes sapidus, inhabiting the Chesapeake Bay has been adapted to seasonal

4 changes of the environmental conditions. In this, the animals halt their physiological process of

5 the growth and reproduction during colder months while they resume these processes as water

6 temperatures increase. We aimed to understand the effect of the elevated temperatures on a

7 disease progression of reo-like virus (CsRLV) and innate immunity of adult female $C$. sapidus.

8 Following a rise in water temperature from 10 to $23^{\circ} \mathrm{C}$, CsRLV levels in infected crabs rose

9 significantly in hemocytes and multiple organs. However, in hemocytes, the elevated

10 temperature had no effect on the levels of three innate immune genes: Cas-ecCuZnSOD-2,

11 CasPPO and CasLpR three carbohydrate metabolic genes: CasTPS, CasGlyP; and CasTreh

12 and the total hemocyte counts (THC). Interestingly, the hemocytes of CsRLV infected animals

13 exposed to $23^{\circ} \mathrm{C}$ for 10 days had significantly elevated levels of Cas-ecCuZnSOD-2 and

14 CasTPS, compared to those of the uninfected ones also exposed to the same condition and

15 compared to hatchery-raised females kept at $23^{\circ} \mathrm{C}$. Despite the lack of changes in $\mathrm{THC}$, the

16 types of hemocytes from the animals with high CsRLV levels differed from those of uninfected

17 ones and from hatchery animals kept at $23^{\circ} \mathrm{C}$ : CsRLV-infected crabs had hemocytes of smaller

18 size with less cytosolic complexity than uninfected crabs. It therefore appears that the change

19 in temperature influences rapid replication of CsRLV in all internal tissues examined. This

20 implies that CsRLV may have broad tissue tropism. Interestingly, the digestive tract (mid- and

21 hindgut) contains significantly higher levels of CsRLV than hemocytes while hepatopancreas

22 and ovary have lower levels than hemocytes. Innate immune responses differ by tissue: midgut

23 and hepatopancreas with upregulated Cas-ecCuZnSOD-2 similar to that found in hemocytes.

24 By contrast, hepatopancreas showed a down-regulated CasTPS, suggesting carbohydrate

25 stress during infection. 


\section{Introduction}

Season affects the physiology and behavior of most animals, including decapod crustaceans, via changes in environmental factors. The growth and reproduction of poikilothermic vertebrates and invertebrates usually depends most strongly on temperature. In the Chesapeake Bay, the blue crab Callinectes sapidus including adult females experiencing low water temperatures during the overwintering period responds to the elevated water temperature in the spring. These adult females at various ovarian development stages increase the levels of vitellogenin ( $\mathrm{VtG}$ ) expression in the hepatopancreas and ovary [1]. In the fall, decreasing water temperature slows the vitellogenic activities in these tissues. During overwintering, adult females show high winter mortality rates, indicating that they may be sensitive to lower temperature [2]. The health status of these dead animals is unknown but it is assumed that their reproductive activity is halted due to low water temperature.

The susceptibility to a disease(s) depends on the initial health status of an individual animal. Stress is intimately associated with predisposition toward infection. It has been wellestablished in decapod crustaceans that changes in environmental conditions including temperature, salinity and dissolved oxygen at extremes are often considered as stressors and are directly reflected in the changes in physiological and metabolic processes [3-9].

In the blue crab, a reo-like virus (CsRLV) has been described that infects mesodermallyand ectodermally-derived tissues, especially hemocytes and epidermal tissues [10, 11]. CsRLV is associated with the majority of mortality in captive molting crabs from shedding facilities, and CsRLV prevalence in wild intermolt crabs is reported to average 20\% [12]. In decapod crustaceans, molting and reproduction are high energy demanding processes that are mutually antagonistic [13]. Therefore, although the mode of infection of this virus to blue crabs has not yet been defined, the inherent changes in physiology of the animals at molting or active ovarian development may be a predisposing factor to CsRLV infection.

We investigated how a shift from low to moderate temperature affects disease 32 overwintered at water temperatures lower than $10^{\circ} \mathrm{C}$. Specifically we aimed to further 33 understand how the animals responded to temperature changes by analyzing the levels of 34 following gene transcripts that are known to be changed due to pathogenic challenges [14-17]: 
prophenoloxidase=PPO; lipoprotein receptor $=\mathrm{LpR}$; extracelluar CuZn superoxide dismutase- $2=$ ecCuZnSOD-2, compared to the animals kept at constant temperatures. The genes involved in carbohydrate energy metabolism (Glycogen phosphorylase $=G l y P$, Trehalose 6-phosphate synthase $=T P S$ and trehalase $=$ Treh) were also examined, since temperature changes affect the energy metabolism of these animals [3]. Additionally, we examined levels of CsRLV in various 6 internal tissues. without CsRLV, as compared to those of the animals kept at constant temperatures.

\section{Materials and Methods}

\subsection{Female brood stock collection}

Adult vitellogenic female crabs (20 in total, carapace width (CW) 110-125 mm, $130 \pm$ $12 \mathrm{~g}$ ) were obtained from the 2013-4 winter dredge survey (http://dnr.maryland.gov/fisheries/crab/dredge.asp) by the Virginia Institute of Marine Science (VIMS). The animals were kept in the indoor-tank at $\sim 10^{\circ} \mathrm{C}$ for two weeks. Each individual animal was wrapped in a wetted newspaper, and transported in a cooler.

\subsection{Temperature exposure}

The animals were kept individually in a pathogen-free quarantine room in the Aquaculture Research Center at the Institute of Marine and Environmental Technology (IMET, Baltimore, MD) in $30 \mathrm{ppt}$ artificial seawater (ASW) (16L: 8D) at ambient room temperature (21$\left.23^{\circ} \mathrm{C}\right)$. Animals were fed a piece of squid $(\sim 10 \mathrm{~g})$ and monitored for daily food consumption and behavioral activity during the sampling period. Water was exchanged at least once a day.

Seven hatchery-raised adult females (110-130 mm CW, $118 \pm 8 \mathrm{~g})$ that had not experienced low temperatures, were used as reference animals [18].

\subsection{Flow cytometric analysis of the hemocytes of C. sapidus}

Hemolymph samplings were carried out on the animals exposed to $23^{\circ} \mathrm{C}$ for 10 days. All

32 hemolymphs were collected between 3-5:00 pm, in order to avoid possible variation in the 33 physiology. The hemolymph was withdrawn directly into an insulin syringe containing $50 \mu \mathrm{l}$ of 34 4\% paraformaldehyde (PFA, made in PBS) at a 1:1 ratio. The hemocytes were separated by 
centrifugation at $800 \mathrm{~g}$ for $10 \mathrm{~min}$ at $4^{\circ} \mathrm{C}$ and re-suspended in $100 \mu \mathrm{l}$ of $4 \% \mathrm{PFA}$, and then stained with SYBR-Green I (Life Technologies) for $15 \mathrm{~min}$ at room temperature with rotation (10 rpm) in the darkness. Hemocytes were counted and analyzed based on their sizes (forward scatter; FSC) and cellular granularity (side scatter; SSC) using a BD Accuri ${ }^{\mathrm{TM}} \mathrm{C} 6$ and CellQuest

5 Program (BD Biosciences). The data for total hemocyte count (THC) are presented as THC/

$6 \mathrm{ml}$ hemolymph $(\mathrm{n})$, where $\mathrm{n}$ is the number of animals.

\subsection{A reo-like virus (CsRLV) test using qPCR assay}

\subsubsection{Hemocytes}

At $23^{\circ} \mathrm{C}$ exposure for 1,10 and 15 days, the hemolymph sample $(100 \mu l)$ was drawn from the arthrodial membrane, located between the first walking leg and the chela, directly into an insulin syringe containing $100 \mu \mathrm{l}$ of anticoagulant $(30 \mathrm{mM}$ trisodium citrate, $26 \mathrm{mM}$ citric acid, $0.1 \mathrm{M}$ glucose, 10mM EDTA, pH. 4.6 [19]). Sample tubes were placed immediately on dry-ice and kept at $-80^{\circ} \mathrm{C}$ until further processing. Total RNA was extracted from these hemolymph samples using Qiazol (Qiagen) as previously described [17, 20]. The quality and quantity of RNA was estimated on a Nanodrop spectrometer (FisherSci). The levels of CsRLV RNA present in the total RNA (=equivalent of $2.5 \%$ of hemolymph) were assayed in triplicate using a one-step RT-qPCR assay with TaqMan® Fast Virus 1-Step Master Mix (Life Technologies) using the primers listed in Table 1 [11]. Standards for the CsRLV qPCR assay were prepared as described [12] ranging from 10 to $10^{6}$ copies. The data are presented as mean $\pm \mathrm{SE}$ copies/100 $\mu$ l hemolymph ( $n$ ) where $n$ is the number of females.

\subsubsection{Tissues}

To examine the levels of CsRLV in internal tissues, hemolymphs were collected as above before the following tissues ( $\sim 50-100 \mathrm{mg}$ wet weight) were dissected on day 17 from the females that had been identified with an CsRLV infection on day 15, and from those that were raised in the hatchery: eyestalk, brain, thoracic ganglia complex, mandibular organ, midgut, hindgut, hepatopancreas, gill, abdominal muscle, antennal gland, ovary, spermathecae, hypodermis and heart. These tissue samples were frozen immediately on dry-ice and kept at $80^{\circ} \mathrm{C}$, until further processing. The procedure for total RNA extraction and its quantification was carried out as described $[17,20]$. The infection levels of CsRLV were examined with total RNA (100 ng) using qPCR assays as above. All samples were assayed in triplicate. The data are shown as mean \pm SE copies/ $\mu$ g total RNA ( $n$ ), where $n$ is the number of females. 
2.5. Hematodinium sp. test using a qPCR assay

The procedures for DNA extraction using a FastDNA kit (Qbiogene) and QPCR analysis

from all the hemolymph samples were as described [21]. In brief, PCR primers listed in Table 1 were designed targeting the reported sequence the Hematodinium sp. 18S rRNA: forward primer (5'-GGTAATCTTCTGAAAACGCATCGT-3'); reverse primer (5'-GTACAAAGGGCAGG

7 GACGTAATC-3'). For qPCR assay, an end-labeled fluorescent probe (5'-6FAM-

8 AATTCCTAGTAAGCGCGAGTCATCAGCTCG-3') was used using TaqMan Universal Master

9 Mix (Applied Biosystems). All samples were assayed in triplicate.

\subsection{Expression analysis using $q P C R$ assays}

One to two $\mu \mathrm{g}$ of total RNA (from hemocytes from the animals exposed to $23^{\circ} \mathrm{C}$ for 10 days and other tissues obtained on day 17) was subjected to $1^{\text {st }}$ strand CDNA synthesis using a Takara PrimeScript $\AA$ Kit by following the manufacturer's instruction. Prior to qPCR assays for expression analysis, the expression levels of arginine kinase were estimated by an end-point RT-PCR assay using PCR conditions as reported [17, 20]. Each cDNA sample containing 25 ng equivalent of total RNA was evaluated in duplicate.

Levels of expression for the following genes were determined using qRT-PCR assays as described [14, 16, 17, 20]: ecCuZnSOD-2, TPS, glycogen phosphorylase (GlyP), trehalase (Treh), prophenoloxidase $(P P O)$ and lipoprotein receptor $(L p R)$. Standard curves for these assays were obtained as described $[14,16,17,20]$. The data are presented as copies/ $\mu \mathrm{g}$ total RNA ( $n$ ), where $n$ is the number of animals.

\subsection{Statistical analysis}

The data were subjected to the normality test using a Kolmogorov-Smirnov test and homogeneity of variances test with a Cochran $\mathrm{C}$ test. The data that did not meet the parametric analysis were analyzed with a non-parametric test. Kruskal-Wallis ANOVA and Median test were used to evaluate the statistical difference (InStat). Statistical significance of one way ANOVA was accepted at $P<0.05$ and post-hoc Tukey's test was adopted to distinguish the source of variation. The data are presented as mean \pm SE $(n)$, where $n$ is the number of 32 animals.

\section{Results}


CsRLV levels were estimated from hemolymph samples collected at $10^{\circ} \mathrm{C}$ and after 10 and 15 days at $23^{\circ} \mathrm{C}$ (Fig. 1). At day 1 , the lowest levels of CsRLV are detected in the hemolymph of two animals with average values of $3.8 \pm 0.16 \times 10^{6}$ copies $/ 100 \mu$ hemolymph $(n=2)$. At $23^{\circ} \mathrm{C}$ for 10 days exposure, the highest levels of CsRLV are found with $4.7 \pm 1.9 \times 10^{8}$ copies/100 $\mu \mathrm{l}$ hemolymph $(\mathrm{n}=6)$. Prior to day 15 sampling, one of these animals died and the

8 other was sacrificed. The remaining four females carried reduced amounts $(P=0.125$,

9 Wilcoxson matched pairs test) of CsRLV in their hemolymph: $9.1 \pm 5.4 \times 10^{7}$ copies/ $100 \mu \mathrm{l}$ 10 hemolymph $(n=4)$. The hatchery raise animals kept at $23^{\circ} \mathrm{C}$ had no CsRLV in their hemocytes.

\subsection{Levels of total hemocyte count}

Because the highest levels of CsRLV were detected in the crabs held at $23^{\circ} \mathrm{C}$ for 10 days, the total hemocyte counts (THC) were determined to see if these high levels of CsRLV might affect THC. Elevated temperature has no significant ( $P=0.14$, One Way, ANOVA, Krustal-Wallis test) effect on THC of the animals with high CsRLV $\left(4.2 \pm 1.4 \times 10^{6} / \mathrm{ml}\right.$ hemolymph, $\mathrm{n}=5)$ as compared to those without CsRLV $\left(7.6 \pm 0.8 \times 10^{6} / \mathrm{ml}\right.$ hemolymph, $\left.\mathrm{n}=12\right)$ and hatchery-raised animals kept at constant $23^{\circ} \mathrm{C}\left(6.6 \pm 1.2 \times 10^{6} / \mathrm{ml}\right.$ hemolymph, $\left.\mathrm{n}=7\right)$.

The size of hemocytes was also measured and was grouped into two size classes using flow cytometry (Figs. 2A-C and D, FSC-H): small for hyaline cells (closed arrow) and large for granulocytes and semigranulocytes (open arrow). CsRLV infection status had a significant effect on the size distribution of hemocytes, but temperature did not. Granulocytes and semigranulocytes are the majority in both the hatchery-raised crabs kept at constant $23^{\circ} \mathrm{C}$ (Fig. 2A) and in animals without CsRLV shifted from $10^{\circ} \mathrm{C}$ to $23^{\circ} \mathrm{C}$ for 10 days exposure (Fig. 2B), with $89.2 \pm 0.9 \%(n=7)$ and $83.6 \pm 3.5 \%(n=12)$ of the cell populations, respectively (Table 2$)$. The animals with CsRLV at $23^{\circ} \mathrm{C}$ for 10 days exposure, however, contained significantly fewer granulocytes and semigranulocytes than the other two groups $(P<0.05)$, with a total of $64.1 \pm$ $11.2 \%(n=5)$. The hatchery-raised animals kept at constant $23^{\circ} \mathrm{C}$, and the animals without CsRLV shifted to $23^{\circ} \mathrm{C}$ for 10 days carried $7.5 \pm 0.6 \%(n=7)$ and $11.4 \pm 2.4 \%(n=12)$ of hyaline cells (Table 2). On the other hand, the animals with CsRLV at $23^{\circ} \mathrm{C}$ for 10 days exposure had 33 significantly higher portions of hyaline cells with $25.8 \pm 8.2 \%(\mathrm{n}=5, P<0.05)$ (Fig. $2 \mathrm{C}$ and Table 34 2). 
Elevated temperature had no effect of the SSC-H of the animals kept at constant at $23^{\circ} \mathrm{C}$ and those elevated to $23^{\circ} \mathrm{C}$ for 10 days, reflecting cytosolic complexity and granularity that differentiate three groups of cells in all three groups (Figs. 2A'-D'). Non-infected and control crabs share a similar pattern (Figs. 2A' and B' and D and D'), while a notably different pattern is found only with the animals carrying CsRLV at $23^{\circ} \mathrm{C}$ for 10 days exposure (Figs. 2C', D and D'). Specifically, the hemocytes obtained from the latter group include higher numbers of cells with

8 less internal complexity (Figs. 2C' and D').

\subsection{Expression analyses of Cas-ecCuZnSOD-2, CasPPO, and CasLpR in hemocytes}

The following three immune response genes in hemocytes were assessed using qRTPCR assays: Cas-ecCuZnSOD-2, CasPPO, and CasLpR. These were chosen due to their known elevation in response to lipopolysaccharide (LPS) injection [16, 17, 20]. When comparing hatchery-raised crabs to non-infected wild crabs, elevated temperature did not influence the levels of Cas-ecCuZnSOD-2, CasPPO, or Cas $L R$ in hemocytes. However animals carrying CsRLV did have higher expression levels of Cas-ecCuZnSOD-2 in their hemocytes, as compared to the other two groups.

The levels of Cas-ecCuZnSOD-2 in animals without CsRLV, and in hatchery-raised crabs, were: $6.5 \pm 2.3 \times 10^{6}$ copies/ $\mu$ g hemocyte total RNA $(n=12)$ and $9.0 \pm 6.7 \times 10^{6}$ copies/ $\mu \mathrm{g}$ hemocyte total RNA $(n=7)$, respectively (Fig. 3A). However, the animals carrying CsRLV at $23^{\circ} \mathrm{C}$ for 10 days exposure contain levels $10-20$ times elevated in the hemocytes $\left(1.7 \pm 0.5 \times 10^{8}\right.$ copies/ $\mu \mathrm{g}$ total RNA, $n=5$ ), as compared to the other two groups.

In regard to the levels of CasPPO (Fig. 3B), the levels of CasPPO of the animals with no CsRLV at $23^{\circ} \mathrm{C}$ for 10 days exposure and those kept constant at $23^{\circ} \mathrm{C}: 1.2 \pm 0.3 \times 10^{7}$ copies/ $\mu \mathrm{g}$ hemocyte total RNA $(n=12)$ and $9.7 \pm 6.7 \times 10^{6}$ copies/ $\mu \mathrm{g}$ hemocyte total RNA $(n=7)$, respectively. However, the animals carrying CsRLV at $23^{\circ} \mathrm{C}$ for 10 days exposure contained slightly higher levels: $2.2 \pm 0.5 \times 10^{7}$ copies/ $\mu$ g hemocyte total RNA $(n=5)$, but these values do not differ significantly from those obtained from the other groups. hemocytes (Fig. 3C). The animals without CsRLV at $23^{\circ} \mathrm{C}$ for 10 days exposure are measured 
with $2.5 \pm 0.7 \times 10^{5}$ copies $/ \mu$ g hemocyte total RNA ( $\left.n=12\right)$, while those carrying CsRLV at the same condition with $6.9 \pm 3.0 \times 10^{5}$ copies $/ \mu$ g hemocyte total RNA $(n=5)$. The animals kept constant at $230 \mathrm{C}$ are determined with $4.1 \pm 2.4 \times 10^{5}$ copies $/ \mu \mathrm{g}$ hemocyte total RNA ( $\left.n=7\right)$.

\subsection{Expression analyses of CasTPS, CasTreh and GlyP in the hemocytes}

Expression of three genes that regulate carbohydrate metabolism in crustaceans were also measured in hemocytes: CasTPS, CasTreh, and CasGlyP (Figs. 4A-C). Elevated temperature had no effect on the levels of CasTPS, CasTreh, and CasGlyP in hemocytes. The animals carrying CsRLV contain higher expression levels of CasTPS, compared to the other two 11 groups.

The levels of CasTPS of the animals without CsRLV at $23^{\circ} \mathrm{C}$ for 10 days exposure and those kept constant at $23^{\circ} \mathrm{C}$ was $2.8 \pm 0.8 \times 10^{6}$ copies/ $\mu$ g hemocyte total RNA $(n=12)$ and 3.1 $\pm 1.0 \times 10^{6}$ copies $/ \mu \mathrm{g}$ hemocyte total RNA ( $\left.n=7\right)$, respectively (Fig. 4A). However, the animals carrying CsRLV at $23^{\circ} \mathrm{C}$ for 10 days exposure contained significantly elevated levels of CasTPS in the hemocytes $\left(7.3 \pm 1.6 \times 10^{6}\right.$ copies/ $\mu$ g total RNA, $\left.n=5\right)$, as compared to the other two groups.

Levels of CasTreh expression shown in Fig.4B do not differ in the animals with or without $\mathrm{CsRLV}$ at $23^{\circ} \mathrm{C}$ for 10 days exposure and those kept constant at $23^{\circ} \mathrm{C}$. The hemocyte cDNAs of the animals without CsRLV at $23^{\circ} \mathrm{C}$ for 10 days exposure contain $8.5 \pm 3.0 \times 10^{5}$ copies/ $\mu \mathrm{g}$ hemocyte total RNA ( $n=12)$; those with CsRLV $\left(1.0 \pm 2.7 \times 10^{6} \mathrm{copies} / \mu \mathrm{g}\right.$ hemocyte total RNA, $n=5)$; and those kept constant at $23^{\circ} \mathrm{C}\left(1.5 \pm 0.8 \times 10^{6} \mathrm{copies} / \mu \mathrm{g}\right.$ hemocyte total RNA, $n=7)$.

For levels of CasGlyP, its expression patterns show similar to Cas $L p R$ shown as in Fig. 3C. Elevated temperature or CsRLV had no effect on the levels of CasGlyP expression in hemocytes (Fig. 4C). The animals without CsRLV at $23^{\circ} \mathrm{C}$ for 10 days exposure are measured with $8.5 \pm 3.7 \times 10^{5}$ copies $/ \mu$ g hemocyte total RNA $(n=12)$, while those carrying CsRLV at the same condition with $1.1 \times 10^{6}$ copies/ $\mu \mathrm{g}$ hemocyte total RNA $(n=5)$. The animals kept constant at $23^{\circ} \mathrm{C}$ are estimated with $1.5 \pm 0.7 \times 10^{6}$ copies $/ \mu \mathrm{g}$ hemocyte total RNA $(n=7)$.

\subsection{Differential CsRLV levels in various internal tissues of adult female C. sapidus}


High levels of CsRLV RNA in hemocytes suggest that other internal organs may be infected with CsRLV. Fourteen different internal organs were dissected on day 17, which represent five physiologically defined functions including the central nervous system (brain, eyestalk and thoracic ganglia complex) and one endocrine tissue; the mandibular organ; the digestive system (midgut, hindgut, and hepatopancreas); the excretory system (gill and antennal gland); the circulatory system (heart); and finally the reproductive system (ovary and

8 spermathecae). The hypodermis and abdominal muscle were also included.

In agreement with previous work [10], there was broad tissue tropism, but surprisingly most tissues contained higher levels of CsRLV than in hemocytes (Fig. 5). As CsRLV infection is known to progress to the CNS, neurological tissues in this study (eyestalk and brain) as expected had higher levels of CsRLV than in hemocytes. Interestingly, the highest levels were observed in midgut with $4.1 \pm 2.6 \times 10^{9}$ copies $/ \mu$ total RNA $(n=4)$. Only two tissues showed lower levels of CsRLV: the hepatopancreas with $4.5 \pm 3.1 \times 10^{7}$ copies/ $\mu \mathrm{g}$ total RNA and ovary

3.6 Expression analyses of Cas-ecCuZnSOD-2 and CasTPS in the digestive system and antennal gland of CsRL V-carrying adult female $C$. sapidus

\subsubsection{Cas-ecCuZnSOD-2}

Since the elevated temperature had no effect on hemocyte populations (Figs. 2A and B), the animals kept at constant $23^{\circ} \mathrm{C}$ were used as controls and data are compared to as CsRLV infected crabs. The cDNA samples derived from hypodermis, antennal gland and digestive system including midgut, hindgut, and hepatopancreas of CsRLV-positive animals maintained at $23^{\circ} \mathrm{C}$ for 17 days and CsRLV-negative controls were assessed for expression of CasecCuZnSOD-2. As shown in Fig. 6A, hepatopancreas, which had lower levels of CsRLV than in hemocytes, contained levels of Cas-ecCuZnSODec-2 significantly $(P=0.002)$ higher in CsRLV infected animals $\left(3.8 \pm 2.2 \times 10^{6}\right.$ copies/ $\mu$ g total $\left.R N A, n=4\right)$ than in controls $\left(9.3 \pm 3.0 \times 10^{4}\right.$ copies/ $\mu \mathrm{g}$ total RNA, $n=7)$. However, the hindgut of CsRLV infected animals also shows higher levels of Cas-ecCuZnSOD-2 $\left(4.7 \pm 1.9 \times 10^{6}\right.$ copies/ $\mu$ g total RNA, $\left.\mathrm{n}=4\right)$ than controls $(4.3 \pm 0.9$ $X 10^{5}$ copies/ $\mu$ g total RNA, $n=7$ ). In other tissues (midgut, hypodermis and antennal gland)

32 there are no significant differences in the levels of Cas-ecCuZnSOD-2 expression between 33 CsRLV infected and controls. 
As shown in Fig. 6B, among the tissues examined from hatchery-raised animals, the

4 hypodermis has the lowest CasTPS expression: $1.9 \pm 1.2 \times 10^{3}$ copies/ $\mu$ g total RNA ( $\left.n=7\right)$.

5 The antennal gland, however, contains the highest CasTPS expression: $2.3 \pm 1.0 \times 10^{5}$ copies/

$6 \mu \mathrm{g}$ total RNA $(\mathrm{n}=7)$. The hepatopancreas shows a significant difference in the levels of CasTPS

7 between CsRLV infected and control females. CsRLV infected animals contain much lower

8 CasTPS expression: $4.3 \pm 1.5 \times 10^{3}$ copies/ $\mu \mathrm{g}$ total RNA $(n=4)$ than hatchery-raised ones: 1.7

$9 \pm 0.4 \times 10^{4}$ copies $/ \mu \mathrm{g}$ total RNA $(n=7)$. In the rest of tissues of CsRLV infected and control

10 females, there were no differences in the levels of CasTPS expression.

\section{Discussion}

This study described progression of CsRLV infections and associated immune responses in adult female $C$. sapidus that have been shifted from $10^{\circ} \mathrm{C}$ to $23^{\circ} \mathrm{C}$.

THC measured in this study was similar to that reported previously in juvenile $C$. sapidus [14]. The CsRLV-infected females exposed at $23^{\circ} \mathrm{C}$ for 10 days, had slightly fewer hemocytes than non-infected wild and naive hatchery-raised adult female crabs kept constant at $23^{\circ} \mathrm{C}$, but the differences were not statistically significant (all three groups of the animals carry similar levels of THC ranging from about 6-8 million cells $/ \mathrm{ml}$ hemolymph). In $P$. monodon and $P$. indicus, a significant reduction in THC is associated with WSSV infection, possibly due to apoptosis of hemocytes, and is closely related to the loss of hemolymph coagulation [22]. It remains to be further ascertained if infection by CsRLV affects THC and coagulation in $C$. sapidus.

The hemolymph of $\boldsymbol{C}$. sapidus, like other decapod crustaceans, carries three types of hemocytes: granulocytes, semi-granulocytes, and hyaline cells [23-25]. Despite similar total hemocyte counts, there is an observed difference in morphology among groups. As expected, such a difference is not related with the elevated temperature but is noted in the infection of CsRLV. Granulocytes and semi-granulocytes (larger cells) seem to be the major types of hemocytes in both hatchery-raised and not-infected animals. Inclusions and cytoplasmic swelling in hemocytes, indicative of CsRLV infection, have been previously observed [12, 26]. However, it is still unknown if CsRLV targets a specific type of hemocyte as found with the 
infection of WSSV, which specifically targets granulocytes and semi-granulocytes of $P$. merguiensis [27]. In this study, on the contrary, CsRLV infected animals show significantly higher portions of small sized and less granulated hemocytes, which may indicate an increase in hyaline cells. It remains to be further studied to define the functional significance of the increase in these cell populations.

The expression levels of genes in hemocytes are changed in the animals infected with CsRLV, while the exposure to elevated temperature from $10^{\circ} \mathrm{C}$ to $23^{\circ} \mathrm{C}$ for 10 days does not affect, compared to the control, hatchery-raised animals kept at constant $23^{\circ} \mathrm{C}$. C. sapidus respond to LPS or lipoteichoid acid (LTA) challenge by elevating the THC, as well as expression of ecCasCuZnSOD-2, CasTPS and CasLpR in hemocytes [16, 17, 20]. In addition, CasPPO levels were examined in this study, as its activation is often associated with crustacean disease responses to pathogens including WSSV [28]. C. sapidus utilizes 4 different types of SOD in various tissues $[17,29,30]$, with the highest expression of Cas-ecCuZnSOD-2 in hemocytes [17]. A significant increase in levels of ecCasCuZnSOD-2 is seen with CsRLV infected animals, as compared to those prepared from non-infected, hatchery-raised adult females. Our finding is congruent with reports showing that WSSV infection increases the levels of ROS and subsequent SOD activity in shrimp [31, 32]. However, it contrasts with other findings that WSSV infection is associated with reduced SOD activity, which subsequently results in lipid peroxidation of the tissues in $P$. monodon [33] and in C. quadricarinatus [34].

It seems that there are different responses in PPO expression to viral infections in crustacean hemocytes. In the hemocytes of $F$. chinensis, the levels of PPO expression are down-regulated [35]. This result somewhat contrasts with the transcriptomic analysis of the whole body of $F$. chinensis with WSSV injection or infection. These shrimp, upon acute WSSV infection, upregulate immune responsive genes including the PPO activating system such as PPOs, their inhibitors (serpins), PPO-activating enzyme, and PO [36]. This suggests that PPO expressed in tissues other than hemocytes may be involved in an innate immune response to WSSV infection. The hemocytes obtained from the female $C$. sapidus with high levels of CsRLV did not show differences in CasPPO expression, indicating that CasPPO expression in the hemocytes may be irrelevant to CSRLV infection at later stages in blue crabs. However, this does not exclude the possibility that PPO may be involved in initial CsRLV infection to 33 hemocytes. 
Viral infection causes changes in metabolic pathways in host cells, particularly in energy metabolism. Particularly, viral infection induces the Warburg effect to support viral replication in endothelial cells and in hemocytes of shrimp [37,38]. The hemocytes of CsRLV infected animals displayed significantly elevated CasTPS expression, similar to what is found with LPS injection [20]. Glucose mobilization via trehalose synthesis is plausible as CsRLV replication in hemocytes may be an energy dependent process. Trehalose is also reported to protect fly and mammalian cells from oxidative damage induced by hypoxia or anoxia [39]. Thus, elevated

8 CasTPS expression for the synthesis of trehalose, as a non-reducing disaccharide, may protect

9 C. sapidus cells from increased oxidative burst which is correlated with upregulation of CasecCuZnSOD-2 expression upon CsRLV infection.

The presence of CsRLV in all the examined tissues indicates its broad tissue tropism, although it still remains to be determined as to what the primary and secondary target tissue(s) of CsRLV are during a natural infection. Interestingly, midgut and hindgut contain much higher levels of CsRLV than hemocytes, whereas ovary and the hepatopancreas have lower amounts of CsRLV than hemocytes. Our results are in agreement with a previous finding in which CsRLV was found in multiple tissues including epidermis, gill, antennal gland, Y-organ and connective tissue [40]. It has been reported that upon experimental infection, via injection of viral particles, CsRLV is also found in gill and leg muscle [12]. Moreover, progressive infection by CsRLV has been reported in $C$. sapidus, with late-stages showing virus spreading into the nervous system including the brain and thoracic ganglia complex, resulting in sluggishness [40]. The levels of CsRLV in these tissues indicate that the primary target of infection may not be the hemocytes or hematopoietic tissue as suggested [41]. Hence, hemolymph sampling, although easy and convenient, may not be the most precise method for monitoring the progression of CsRLV infection.

The two genes that are upregulated in hemocytes by the infection of CsRLV, CasecCuZnSOD-2 and CasTPS, were examined in tissues that contain higher levels of CsRLV than hemocytes: midgut, hindgut, hypodermis and antennal gland, together with the hepatopancreas which showed lower levels of CsRLV. In regard to Cas-ecCuZnSOD-2 expression, tissues show differential responses to a CsRLV infection, although the basal levels of CasecCuZnSOD-2 expression are constant. CsRLV infection elevates Cas-ecCuZnSOD-2 expression in hindgut and hepatopancreas, similar to the effect in hemocytes. 
In contrast to what was observed in hemocytes, none of the other tissues showed an elevation in CasTPS expression. The basal levels of CasTPS in the tissues varied significantly, and did not directly reflect the level of CSRLV in these tissues. No changes were found in the levels of CasTPS in any tissue examined except the hepatopancreas. In contrast to the hemocytes, where higher CasTPS expression was associated with CsRLV infection, the hepatopancreas in CsRLV infected animals had significantly reduced CasTPS expression. Levels of carbohydrate contents were not determined in this tissue. Trehalose is the major carbohydrate in hemolymph and hepatopancreas of $C$. sapidus [20,42]. The reduced levels of CasTPS may be related to the nutritional condition of these crabs in that, in the later stages CsRLV infection, infected animals often do not feed or reduce their food intake (personal observation).

Sudden changes in the environmental conditions constitute stress and influence the metabolic and physiological status of animals. A high mortality of $C$. sapidus females has often been observed immediately after arrival to the IMET facility (personal observation). Water temperature at the spawning ground of $C$. sapidus in the Chesapeake Bay ranges from $\sim 4^{\circ}$ to $26^{\circ} \mathrm{C}$. The animals were caught in February, 2014 at $<4 \stackrel{\circ}{ }$ water temperature (http://tidesandcurrents.noaa.gov/physocean.html) and kept at $\sim 10^{\circ} \mathrm{C}$ (VIMS), prior to transfer. Particularly, elevation of water temperature from $\sim 10^{\circ} \mathrm{C}$ to $23^{\circ} \mathrm{C}$ may affect both host and pathogen, as it could be stressful to the animals. On the other hand, it may provide a favorable condition for the replication of CsRLV resulting in the manifestation and the increase in the numbers of CSRLV at day 10, as seen with WSSV in crayfish [43].

The physiological and metabolic status of an individual animal plays a critical role in infection and disease progression [44]. However, little is known about the relationship between susceptibility to infections and physiological events such as molting and vitellogenesis: two energetically demanding processes. Particularly, C. sapidus adult females engage reproductive phases immediately after the pubertal-terminal molt and continue throughout their adulthood $[45,46]$. In the Chesapeake Bay, the reproductive activity of these animals depends on season and is high during the months of warmer water temperatures [1]. Given that energy available for allocation to vitellogenesis competes with other physiological actions such as activity,

32 homeostasis, maintenance, etc [47, 48], the cost of increased reproductive activity of those

33 females in response to elevated water temperature in the spring may reduce their fitness as a 34 trade-off $[47,48]$, resulting in being more susceptible to potential pathogens. 
Like vertebrates, innate immune functions of invertebrates provide the first lines of defense in to an infectious non-pathogenic or pathogenic agent [49]. In challenge experiments with WSSV or bacteria, shrimp and other crustacean species show changes in the expression of genes in hemocytes and other tissues that are known to be involved in innate immunity [36, 50-

55]. The hemocytes of $C$. sapidus respond to injections of LPS and LTA with elevated expression of TPS [20], LpR [16], and SOD [17]. Moreover, reduced feeding behavior and food consumption that are often influenced by the status of infections may further suppress the expression of immune-related genes, which subsequently increase susceptibility to other opportunistic pathogens. The degree of infections may also reflect the various metabolic costs of such immune reactions [56]. Moreover, the reproductively active adult females may have an increase in the susceptibility to infection, as we have observed in this study that all CsRLV infected females were at late vitellogenic stages. Life-stage dependent infection rate and tradeoffs between reproduction and immune reactions upon an infection need to be further studied.

To date, it is not known what the exact mode of viral entry is in decapod crustaceans. It has been suggested that infection by WSSV may occur through an interaction between the host membrane transporter Glut 1 and the viral envelope protein, VP53A [57]. In vertebrate systems, reoviruses have been known to bind to the junctional adhesion molecule $A$ (JAM-A), followed by activation of integrins [58]. At the organismal level, the mode of CsRLV infection may be through cannibalism or horizontal transmission via sharing water with infected crabs. If the infection indeed occurred in the holding tank, we suggest that it may be due to horizontal transmission as these females significantly reduce food intake at lower temperature. The fact that infected females were at late vitellogenic stages suggests the importance of physiological status of the animals in disease susceptibility. The precise mode and primary site of CsRLV infection need to be studied using hatchery-raised animals such that life stage and physiological states (i. e., molt and vitellogenic stages) are defined and tractable. crabs. The work was supported by a NSF program grant to JSC (1146774), NSF-UMES

32 CREST center grant to JSP and JSC (1036586) and NOAA Living Marine Resources

33 Cooperative Science Center (NOAA Award No. NA11SEC4810002). This article is contribution 
1 no. $x x x x$ of the University of Maryland Center for Environmental Science and contribution no. $x x-$ $2 x x x x$ of the Institute of Marine and Environmental Technology. 
3 [1] Thongda W, Chung JS, Tsutsui N, Zmora N, Katenta A. Seasonal variations in 4 reproductive activity of the blue crab, Callinectes sapidus: Vitellogenin expression and levels of 5 vitellogenin in the hemolymph during ovarian development. Comp Bioch and Physiol A Mol

6 Interg Physiol. 2015 179:35-43.

7 [2] Rome MS, Young-Williams AC, Davis GR, Hines AH. Linking temperature and salinity 8 tolerance to winter mortality of Chesapeake Bay blue crabs (Callinectes sapidus). Journal of

9 Experimental Marine Biology and Ecology. 2005 319:129-45.

[3] Chung JS, Zmora N. Functional studies of crustacean hyperglycemic hormone (CHHs) of the blue crab, Callinectes sapidus- the expression and release of $\mathrm{CHH}$ in eyestalk and pericardial organ in response to environmental stress. FEBS J. 2008 275:693-704.

[4] Chung JS, Zmora N, Tsutsui N, Katayama H. Crustacean hyperglycemic hormone (CHH) neuropeptides family: function, titer, and binding to target tissues. Gen Comp Endocrinol. 2010 $166: 447-54$.

[5] Stentiford GD, Chang ES, Chang SA, Neil DM. Carbohydrate dynamics and the crustacean hyperglycemic hormone $(\mathrm{CHH})$ : effects of parasitic infection in Norway lobsters (Nephrops norvegicus). Gen Comp Endocrinol. 2001 121:13-22.

[6] Webster SG, Keller R, Dircksen $\mathrm{H}$. The $\mathrm{CHH}$-superfamily of multifunctional peptide hormones controlling crustacean metabolism, osmoregulation, moulting and reproduction. Gen Comp Endocrinol. 2012 175:217-33.

[7] Chung JS, Webster SG. Dynamics of in vivo release of molt-inhibiting hormone and crustacean hyperglycemic hormone in the shore crab, Carcinus maenas. Endocrinology. 2005 146:5545-51.

[8] Chang ES, Keller R, Chang SA. Quantification of crustacean hyperglycemic hormone by ELISA in hemolymph of the lobster, Homarus americanus, following various stresses. Gen Comp Endocrinol. 1998 111:359-66.

[9] Holman JD, Burnett KG, Burnett LE. Effects of hypercapnic hypoxia on the clearance of Vibrio campbellii in the Atlantic blue crab, Callinectes sapidus Rathbun. Biol Bull. 2004 206:18896.

[10] Johnson PT. Viral diseases of marine invertebrates. In: Kinne O, Bulnheim HP, editors. Diseases of marine organisms. Hamburg: Anstalt Helgoland; 1984, p. 65-98.

[11] Flowers E, Hanif A, Simmonds K, Messick G, Sullivan L, Schott E. PCR-based prevalence of a fatal reovirus of the blue crab, Callinectes sapidus (Rathbun) along the northern Atlantic coast of the USA. J Fish Diseases. 2015 DOI: 10.1111/jfd.12403. 
[12] Bowers HA, Messick GA, Hanif A, Jagus R, Carrion L, Zmora O, et al. Physicochemical properties of double-stranded RNA used to discover a reo-like virus from blue crab Callinectes sapidus. Dis Aquat Organ. 2010 93:17-29.

[13] Aiken DE, Waddy SL. Reproductive biology. In: Cobb JS, Philips BF, editors. The Biology and Management of Lobsters: Physiology and Behavior New York: Academic Press; 1980, p. 215-76.

[14] Alvarez JV, Chung JS. Cloning of prophenoloxidase from hemocytes of the blue crab, Callinectes sapidus and its expression and enzyme activity during the molt cycle. Fish \& Shellfish Immunology. 2013 35:1349-58.

[15] Liu Y-T, Chang C-I, Hseu J-R, Liu K-F, Tsai J-M. Immune responses of prophenoloxidase and cytosolic manganese superoxide dismutase in the freshwater crayfish Cherax quadricarinatus against a virus and bacterium. Molecular Immunology. 2013 56:72-80.

[16] Tsutsui N, Chung JS. A novel putative lipoprotein receptor (CasLpR) in the hemocytes of the blue crab, Callinectes sapidus: Cloning and up-regulated expression after the injection of LPS and LTA. Fish Shellfish Immunol. 2012 32:469-75.

[17] Chung JS, Bachvaroff TR, Trant J, Place A. A second copper zinc superoxide dismutase (CuZnSOD) in the blue crab Callinectes sapidus: Cloning and up-regulated expression in the hemocytes after immune challenge. Fish Shellfish Immunol. 2012 32:16-25.

[18] Zmora O, Findiesen A, Stubblefield J, Fraenkel V, Zohar Y. Large-scale juvenile production of the blue crab Callinectes sapidus. Aquaculture. 2005 244:129-39.

[19] Söderhäll K, Smith VJ. Separation of the haemocyte populations of Carcinus maenas and other marine decapods and prophenoloxidase distribution Dev Comp Immunol. 1983 7:22939.

[20] Chung JS. A trehalose 6-phosphate synthase gene of the hemocytes of the blue crab, Callinectes sapidus: cloning, the expression, its enzyme activity and relationship to hemolymph trehalose levels. Saline Systems. 2008 4:18.

[21] Nagle L, Place AR, Schott EJ, Jagus R, Messick G, Pitula JS. Real-time PCR-based assay for quantitative detection of Hematodinium $\mathrm{sp}$. in the blue crab Callinectes sapidus. Dis Aquat Organ. 2009 84:78-87.

[22] Hameed ASS, Sarathi M, Sudhakaran R, Balasubramanian G, Musthaq SS. Quantitative assessment of apoptotic hemocytes in white spot syndrome virus (WSSV)-infected penaeid shrimp, Penaeus monodon and Penaeus indicus, by flow cytometric analysis. Aquaculture. 2006 256:111-20.

[23] Hose J, Martin G, Gerard AS. A decapod hemocyte classification scheme integrating morphology, cytochemistry, and function. Biol Bull. 1990 178:33-45. 
$2 \quad$ Procambarus clarkii blood cells. . Dev Comp Immunol. 1993 17:389-97.

3 [25] Wenli C, Shields JD. Characterization and primary culture of hemocytes from the blue

4 crab, Callinectes sapidus. Trans Chinese Crustac Soc. 2007 5:25-35.

[26] Johnson PT. A viral disease of the blue crab, Callinectes sapidus: histopathology and differential diagnosis. J Invertebr Pathol. 1977 29:201-9.

[27] Wang YT, Liu W, Seah JN, Lam CS, Xiang JH, Korzh V, et al. White spot syndrome virus (WSSV) infects specific hemocytes of the shrimp Penaeus merguiensis. Dis Aquat Organ. 2002 52:249-59.

[28] Cerenius L, Söderhäll K. The prophenoloxidase-activating system in invertebrates. Immunol Rev. 2004 198:116-26.

[29] Brouwer M, Brouwer TH, Grater W, Enghild J, Thogersen I. The paradigm that all oxygen-respiring eukaryotes have cytosolic CuZn-superoxide dismutase and that Mnsuperoxide dismutase is localized to the mitochondria does not apply to a large group of marine arthropods. Biochemistry. 1997 36:13381-8.

[30] Brouwer M, Hoexum Brouwer T, Grater W, Brown-Peterson N. Replacement of a cytosolic copper/zinc superoxide dismutase by a novel cytosolic manganese superoxide dismutase in crustaceans that use copper (haemocyanin) for oxygen transport. Biochem J. 2003 374:219-28.

[31] Ji PF, Yao CL, Wang ZY. Reactive oxygen system plays an important role in shrimp

Litopenaeus vannamei defense against Vibrio parahaemolyticus and WSSV infection. Dis Aquat Organ. 2011 96:9-20.

[32] Yang J-Y, Chang C-I, Liu K-F, Hseu J-R, Chen L-H, Tsai J-M. Viral resistance and immune responses of the shrimp Litopenaeus vannamei vaccinated by two WSSV structural proteins. Immunol Lett. 2012 148:41-8.

[33] Mathew S, Nair AKK, Anandan R, Gopalan P, Nair NV, Devadasan K. Biochemical studies on changes associated with enzymes of glucose metabolism in white spot syndrome virus (WSSV) infected with Penaeus monodon (Fabricius) African J Biotechnol. 2007 6:1944-8.

[34] Wang D-L, Zuo D, Wang L-M, Sun T, Wang Q, Zhao Y-L. Effects of white spot syndrome Fish Shellfish Immunol. 2012 32:645-50. 
1 [36] Li S, Zhang X, Sun Z, Li F, Xiang J. Transcriptome analysis on chinese shrimp

2 Fenneropenaeus chinensis during WSSV acute infection. PLoS ONE. 20138 e58627.

3 doi:10.1371/journal.pone.005862.

4 [37] Delgado T, Carroll PA, Punjabi AS, Margineantu D, Hockenbery DM, Lagunoff M. 5 Induction of the Warburg effect by Kaposi's sarcoma herpesvirus is required for the 6 maintenance of latently infected endothelial cells. Proc Natl Acad Scis. 2014

$7 \quad 10.1073 /$ pnas.1004882107.

8 [38] Chen IT, Aoki T, Huang YT, Hirono I, Chen TC, Huang JY, et al. White spot syndrome 9 virus induces metabolic changes resembling the warburg effect in shrimp hemocytes in the early stage of infection. J Virol. 2011 85:12919-28.

11 [39] Chen Q, Haddad GG. Role of trehalose phosphate synthase and trehalose during 12 hypoxia: from flies to mammals. J Exp Biol. 2004 207:3125-9.

13 [40] Johnson PT. Diseases caused by viruses, rickettsiae, bacteria, and fungi. In:

14 Provenzano AJ, editor. The Biology of Crustacea. New York: Academic Press; 1983, p. 1-78.

[41] Shields JD, Overstreet RM. Diseases, Parasites, and Other Symbionts. In: Kennedy VS, 16 Cronin LE, editors. The Blue Crab. College Park Maryland Sea Grant; 2007, p. 299-417.

17 [42] Chung JS. An insulin-like growth factor found in hepatopancreas implicates 18 carbohydrate metabolism of the blue crab Callinectes sapidus. Gen Com Endocrinol. 2014 19 199:56-64.

20 [43] Jiravanichpaisal P, Söderhäll K, Söderhäll I. Effect of water temperature on the immune response and infective pattern of white spot syndrome virus (WSSV) in freshwater crayfish. Fish Shellfish Immunol. 2004 17:265-75.

23 [44] Sniezko SF. The effects of environmental stress on outbreaks of infectious diseases of 24 fishes. J Fish Biol. 1974 6:197-208.

25 [45] Jivoff PR, Hines AH, Quackenbush LS. Reproductive biology and embryonic 26 development. In: Kennedy VS, Cronin LE, editors. The Blue Crab Callinectes sapidus. College 27 Park, MD: Maryland Sea Grant College; 2007, p. 255-98.

28 [46] Zmora N, Trant J, Chan S-M, Chung JS. Vitellogenin and its messenger RNA during 29 ovarian development in the female blue crab, Callinectes sapidus: Gene expression, synthesis, 30 transport and cleavage. Biol Reprod. 2007 77:138-46.

31 [47] Williams GC. Natural selection, The costs of reproduction, and a refinement of Lack's 32 principle. Am Nat. 1966 100:687-90.

33 [48] Zera AJ, Harshman LG. The physiology of life history trade-offs in animals. Annu Rev 34 Ecol Syst. 2001 32:65-126. 
1 [49] Iwanaga S, Lee BL. Recent Advances in the Innate Immunity of Invertebrate Animals. J

2 Biochem Mol Biol. 2005 38:128-50.

3 [50] Rojtinnakorn J, Hirono I, Itami T, Takahashi Y, Aoki T. Gene expression in haemocytes 4 of kuruma prawn, Penaeus japonicus, in response to infection with WSSV by EST approach.

5 Fish \& Shellfish Immunol. 2002 13:69-83.

6 [51] Kulkarni AD, Kiron V, Rombout JHWM, Brinchmann MF, Fernandes JMO, Sudheer NS, 7 et al. Protein profiling in the gut of Penaeus monodon gavaged with oral WSSV-vaccines and

8 live white spot syndrome virus. Proteomics. 2014:DOI: 10.1002/pmic.201300405.

9 [52] Liu H-p, Chen R-y, Zhang Q-x, Peng H, Wang K-j. Differential gene expression profile 10 from haematopoietic tissue stem cells of red claw crayfish, Cherax quadricarinatus, in response 11 to WSSV infection. Dev Comp Immunol. 2011 35:716-24.

12 [53] Mathew S, Kumar KA, Anandan R, Nair Viswanathan PG, Devadasan K. Changes in 13 tissue defence system in white spot syndrome virus (WSSV) infected Penaeus monodon. Comp 14 Biochem Physiol C Toxicol Pharmacol. 2007 145:315-20.

15 [54] Tian J, Chen J, Jiang D, Liao S, Wang A. Transcriptional regulation of extracellular 16 copper zinc superoxide dismutase from white shrimp Litopenaeus vannamei following Vibrio 17 alginolyticus and WSSV infection. Fish Shellfish Immunol. 2011 30:234-40.

[55] Wang B, Li F, Dong B, Zhang X, Zhang C, Xiang J. Discovery of the genes in response to white spot syndrome virus (WSSV) infection in Fenneropenaeus chinensis through cDNA microarray. Mar Biotechnol. 2006 8:491-500.

21 [56] Lochmiller RL, Deerenberg C. Trade-offs in evolutionary immunology: just what is the 22 cost of immunity? . Oikos. 2000 88:87-98.

23 [57] Huang H-T, Leu J-H, Huang P-Y, Chen L-L. A Putative cell surface receptor for white 24 spot syndrome virus Is a member of a transporter superfamily PLoS ONE. 2012 7:e33216.

25 [58] Schulz WL, Haj AK, Schiff LA. Reovirus uses multiple endocytic pathways for cell entry J 26 Virol. 2012 86:12665-75. 
Figure legends

2 Figure 1. The number of a CsRLV in the hemolymph of the infected female crabs exposed at $23^{\circ} \mathrm{C}$ for 1,10 , and 15 days. The samples were assayed in triplicated using a CsRLV pPCR assay. Standards are ranged from $10-10^{6}$ copies/well. Data are presented as mean \pm SE $(n=2-$ 6) CsRLV copies/100 $\mu$ l hemolymph eqv.

Figure 2. Flow cytometric analysis of the hemocytes obtained from the experimental animals exposed at $23^{\circ} \mathrm{C}$ for 10 days with CsRLV infected ( $C$ and $\left.C^{\prime}\right)$, not-infected ( $B$ and $B^{\prime}$ ) and hatchery-raised adult females ( $\mathrm{A}$ and $\mathrm{A}^{\prime}$ ). $\mathrm{A}-\mathrm{C}$ ) are obtained by $\mathrm{FSH}-\mathrm{H}$. Open arrow: larger sized cells and closed arrow: smaller sized cells; A'-C') are obtained by SSC-H. Arrows indicate three groups of cells. D and D') show the size and the granularity distribution of hemocytes of all three groups, respectively. CsRLV-I: CsRLV infected; N-I: not infected; and H-R: hatcheryraised.

Figure 3. Expression analyses of Cas-ecCuZnSOD-2 (A), CasPPO (B), and CasLpR (C) in the hemocytes of the experimental animals exposed at $23^{\circ} \mathrm{C}$ for 10 days: CsRLV not-infected $(n=12)$ and infected with CsRLV $(n=5)$, compared to the hatchery-raised adult animals kept constant at $23^{\circ} \mathrm{C}(n=7)$. Data are presented as mean \pm SE copies/ $\mu \mathrm{g}$ total RNA. Letters are noted for statistical significance at $P<0.05$ and N. D. = No difference

Figure 4. Expression analyses of CasTPS (A), CasTreh (B), and CasGlyP (C) in the hemocytes of the experimental animals exposed at $23^{\circ} \mathrm{C}$ for 10 days: CsRLV not-infected $(n=12)$ and infected with CsRLV $(n=5)$, compared to the hatchery-raised adult animals kept constant at $23^{\circ} \mathrm{C}(n=7)$. Data are presented as mean \pm SE copies/ $\mu \mathrm{g}$ total RNA. Letters are noted for statistical significance at $P<0.05$ and N. D. $=$ No difference

Figure 5. The number of a CsRLV in the various internal organs of the infected female crabs exposed at $23^{\circ} \mathrm{C}$ for 17 days. The samples were assayed in triplicated using a CsRLV pPCR assay. Dotted line indicates the levels of CsRLV in hemocytes. Data are presented as mean \pm SE copies of CsRLV/25 ng total tissue RNA.

Figure 6. Expression analyses of Cas-ecCuZnSOD-2 (A) and CasTPS (B) in various tissue cDNAs of the infected female crabs exposed at $23^{\circ} \mathrm{C}$ for 17 days (closed bar, $n=5$ ) and the hatchery-raised adult females kept constant at $23^{\circ} \mathrm{C}$ (open bar, $\mathrm{n}=7$ ). Data are presented as mean \pm SE copies/ $\mu$ g total tissue RNA. Statistical significance is examined using one way ANOVA followed by a post hoc assay, Krustal-Wallis test for the different tissues in each group and Student's $t$ test (nonparametric two tails) of a tissue obtained the CsRLV infected animals exposed to $23^{\circ} \mathrm{C}$ for 17 days and hatchery raised animals kept constant at $23^{\circ} \mathrm{C}$. Significance is 
1 Table 1. List of primers used for qPCR assays

\begin{tabular}{|l|l|l|}
\hline Gene & Primer sequence (5'-3') & References \\
\hline CsRLV & $\begin{array}{l}\text { TGCGTTGGATGCGAAGTGACAAAG (F) } \\
\text { GCGCCATACCGAGCAAGTTCAAT (R) }\end{array}$ & $\begin{array}{l}\text { Bowers et al., 2010 } \\
\text { Flower et al, 2015 }\end{array}$ \\
\hline $\begin{array}{l}\text { Hematodinium } \\
\text { sp. }\end{array}$ & $\begin{array}{l}\text { GGTAATCTTCTGAAAACGCATCGT (F) } \\
\text { GTACAAAGGGCAGG GACGTAATC (R) }\end{array}$ & Pitula et al., 2012 \\
\hline TPS & $\begin{array}{l}\text { ATGTTGGTGGAACACAATTCAAGGAC (QF) } \\
\text { CTTTGTATAATCTAACCGATCCACTC (QR) }\end{array}$ & Chung, 2008 \\
\hline LpR & $\begin{array}{l}\text { CATGACAGCAAGGACAAGAGGTT (QF) } \\
\text { CCTCACTTGCTCTCCATGAGTGAT(QR) }\end{array}$ & Tsutsui and Chung, 2012 \\
\hline ecCuZnSOD-2 & $\begin{array}{l}\text { TCAACAAGGAACCCTTGGTCTCGGA (QF) } \\
\text { TGTACGTGGAATCCGTGCTTGCCCGG (QR) }\end{array}$ & Chung et al., 2012 \\
\hline Treh & $\begin{array}{l}\text { GCAGAGAGTGGATGGGA (QF) } \\
\text { CCCTGACAGCAGCAAGCCCTCA (QR) }\end{array}$ & Chung, 2008 \\
\hline PPO & $\begin{array}{l}\text { CACCTCTTCATCCATCACAAACTC (QF) } \\
\text { CAACCACACCCACAGAAGTTAAAG (QR) }\end{array}$ & Alvarez and Chung, 2013 \\
& $\begin{array}{l}\text { TATGAGTATGGTATTTTCGCCCAGAAGATCA } \\
\text { (QF) } \\
\text { AGGGATCATGTACTCAGGGCGGGCCTTC } \\
\text { (QR) }\end{array}$ & \\
\hline
\end{tabular}

2 
1 Table 2. Size distribution in the population of hemocytes present in the hemolymph of the 2 CsRLV infected and non-infected animals exposed at $23^{\circ} \mathrm{C}$ for 10 days and non-infected 3 hatchery raised kept constant at $23^{\circ} \mathrm{C}$

4

\begin{tabular}{|l|l|l|l|l|}
\hline Group & \multicolumn{2}{|l|}{ Small size (\%) } & Large size (\%) & \\
\hline & Mean \pm SE (n) & $P<0.05$ & Mean \pm SE (n) & $P<0.05$ \\
\hline $\begin{array}{l}\text { Hatchery- } \\
\text { raised }\end{array}$ & $7.5 \pm 0.6(7)$ & $\mathrm{a}$ & $89.2 \pm 0.9(7)$ & $\mathrm{a}$ \\
\hline Not-infected & $11.4 \pm 2.4(12)$ & $\mathrm{a}$ & $83.6 \pm 3.5(12)$ & $\mathrm{a}$ \\
\hline $\begin{array}{l}\text { CsRLV } \\
\text { infected }\end{array}$ & $25.8 \pm 8.2(5)$ & $\mathrm{b}$ & $64.1 \pm 11.2(5)$ & $\mathrm{b}$ \\
\hline
\end{tabular}

5 
Chung et al., Figure 1

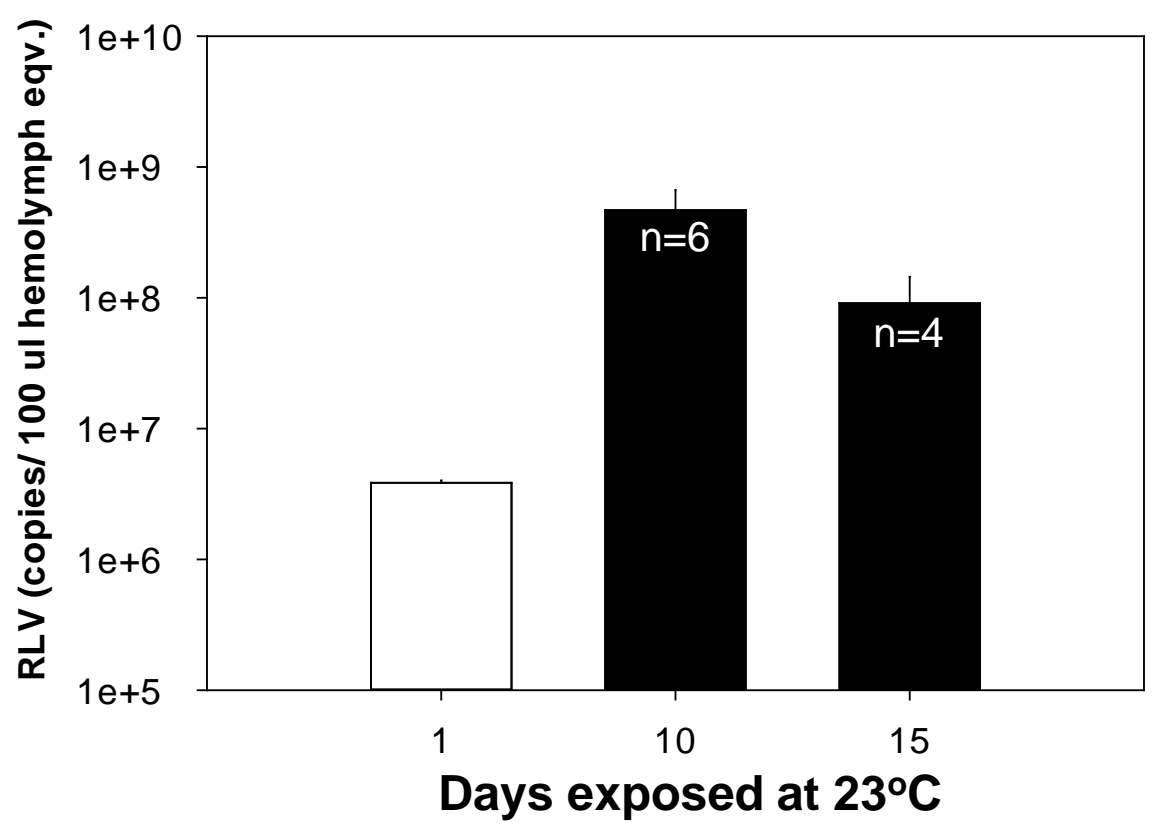


Chung et al., Figures 2A-D
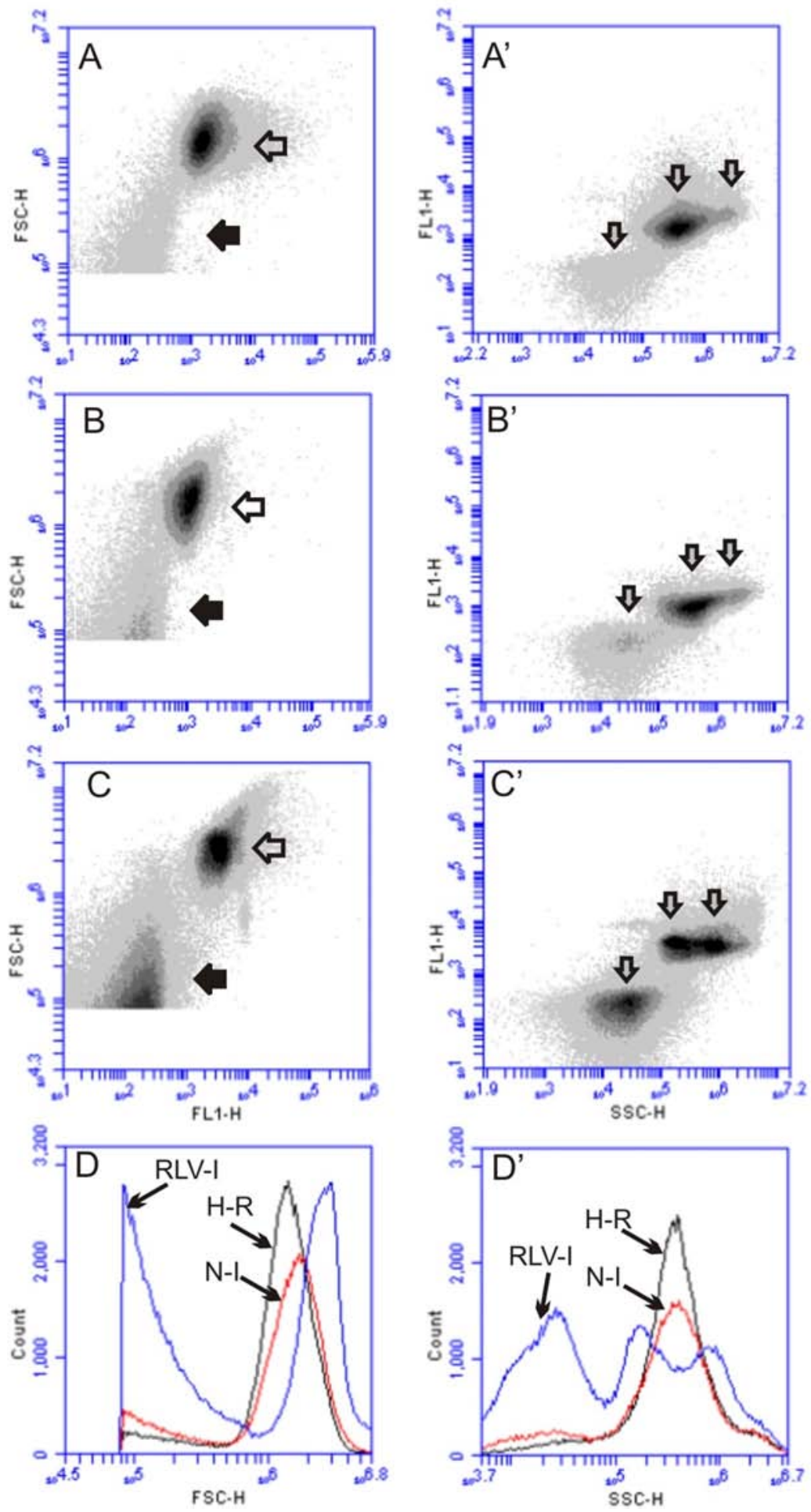
Chung et al., Figures $3 A-C$
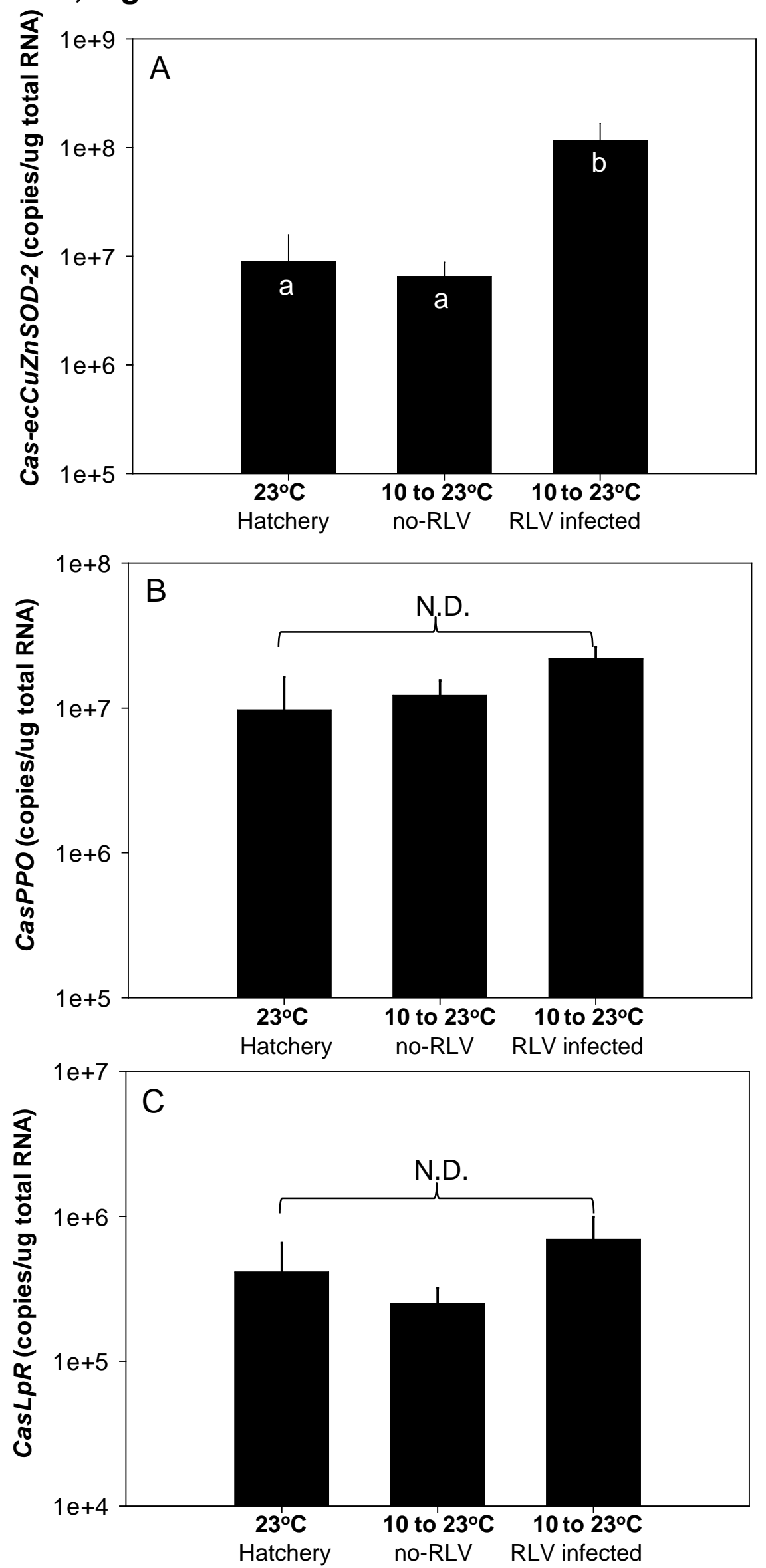


\section{Chung et al., Figures 4A-C}
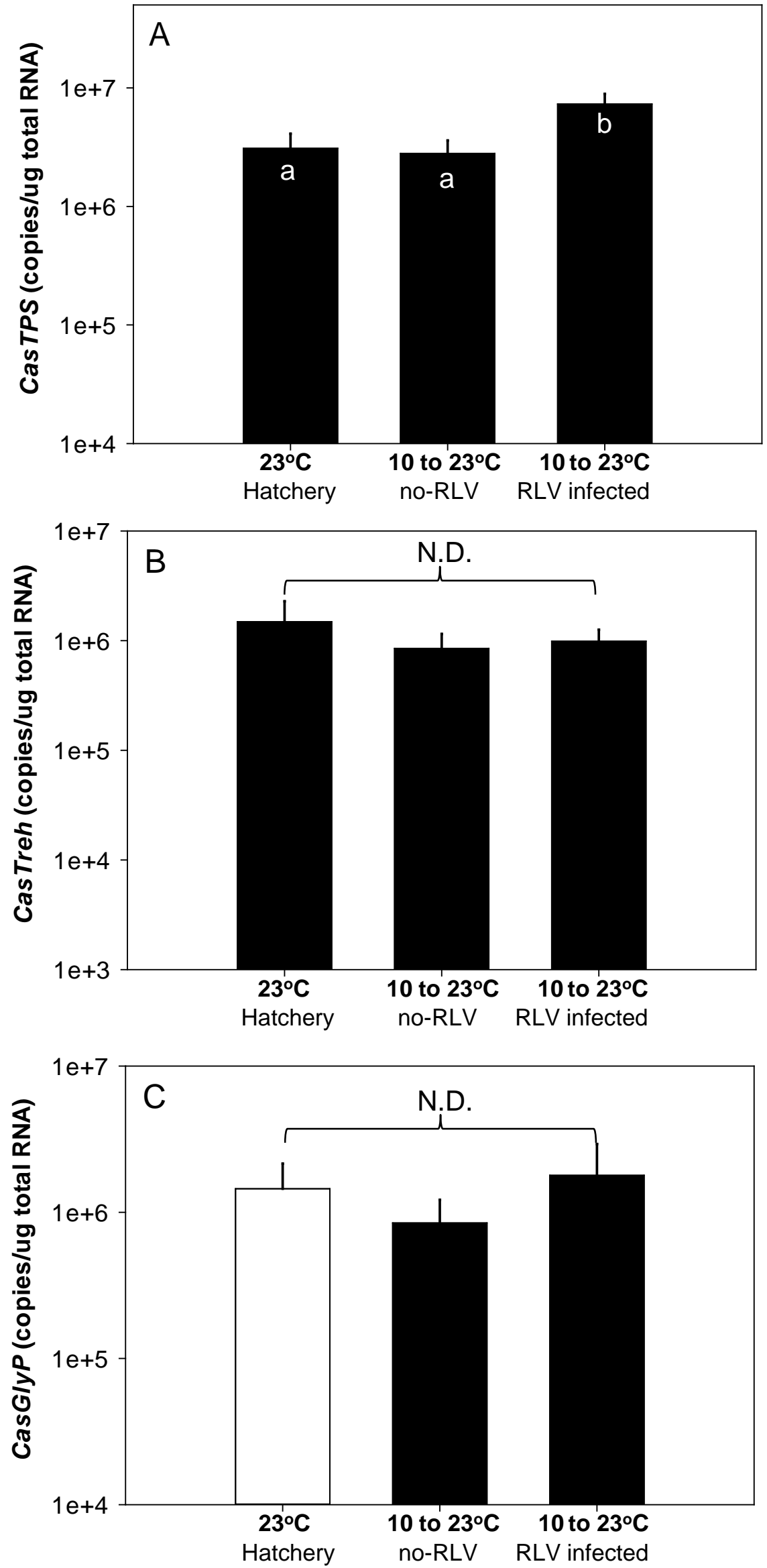


\section{Chung et al., Figure 5}

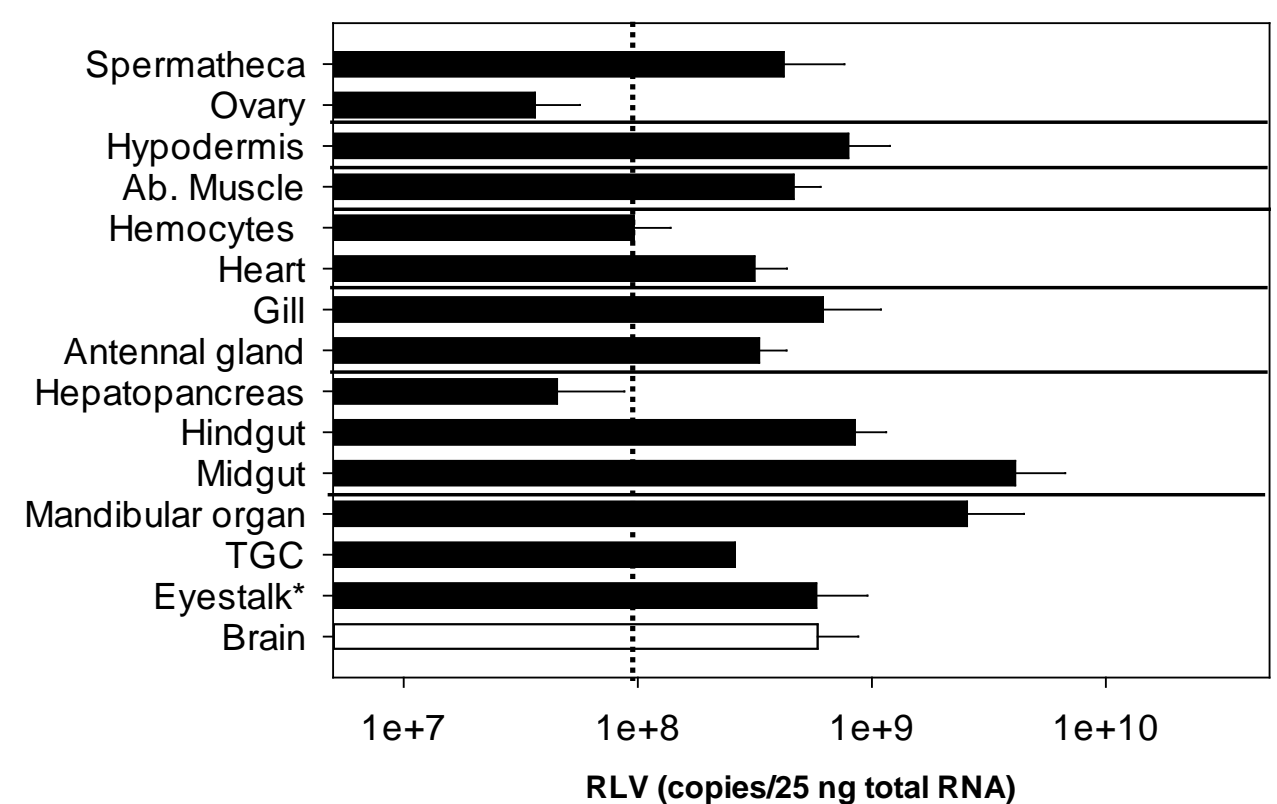




\section{Chung et al., Figures 6A and B}
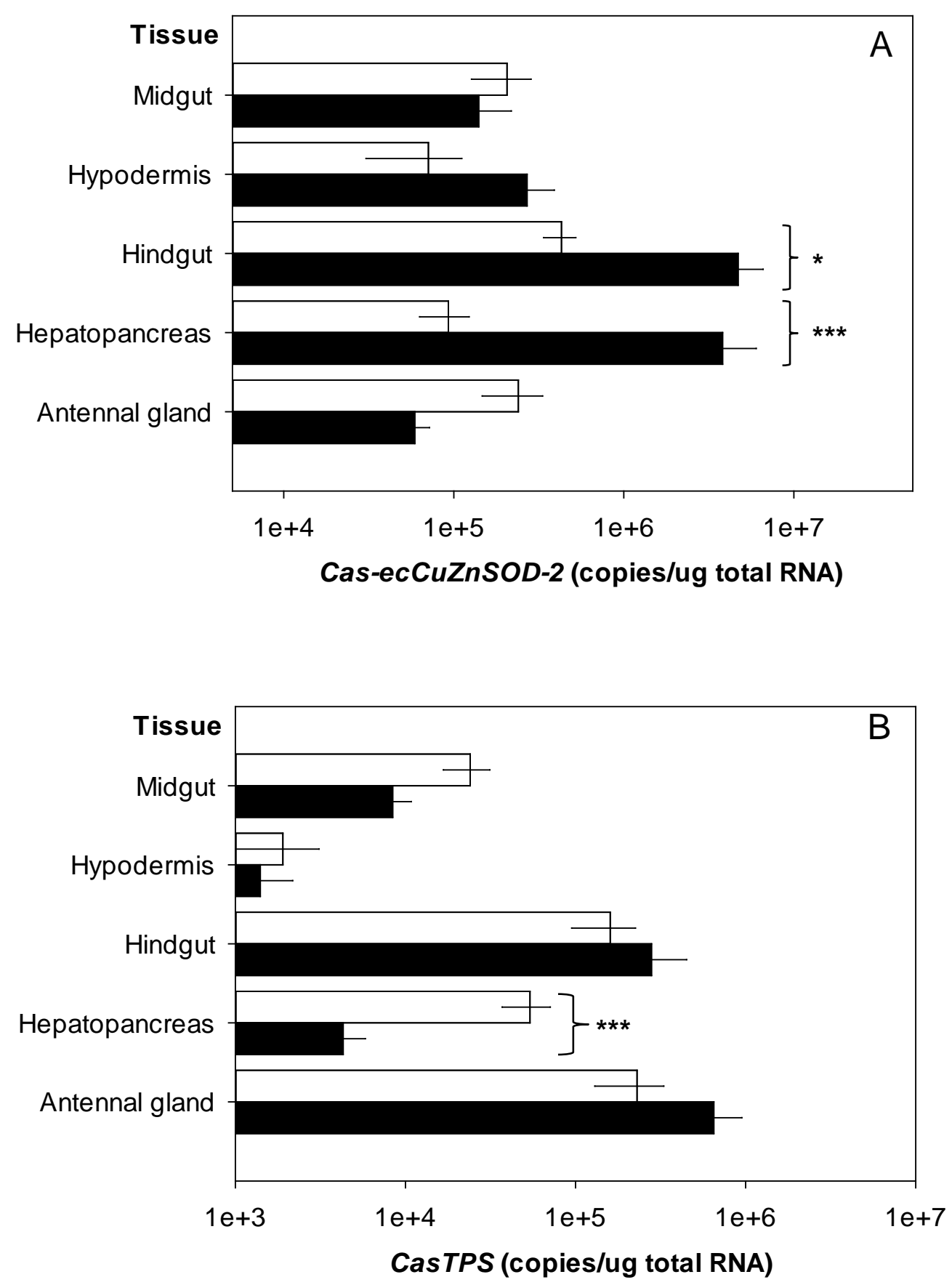